\title{
HET LÒDA'SCH,
}

in vergelijking met het Galèla'sch dialect op Halmaheira.

\author{
G E V O L G
}

DOOR

\section{LÒDA'SCHE TEKSTEN EN VERHALEN.}

DOOR

M. J. VAN BAARDA,

Zendeling van de Utrechtsche Zendeling Vereeniging op Halmaheira. 


\section{N L E I D I N G.}

Het Lòda'seh dialect wordt gesproken in het district Lòda, op de N. W. kust van Halmaheira's noordelijk schiereiland. Het strekt zich uit van de op de Noordpunt van Halmaheira gelegen negory Supu (die half Galèla'sch, half Lòda'sch gebied is) tot Roni ma dòto (kaap Roni), waar het paalt aan 't district Tolofūo en ligt dus tusschen $1^{\circ} 35^{\prime}$ en $2^{\circ} 20^{\prime} \mathrm{N}$. B. en $127^{\circ} 20$ en $128^{\circ} \mathrm{O}$. L. Er bij behooren twee eilandengroepen: de Zuider-Lòda-eil. (Kahatola, Duwa-sétan, Sidūa, Maré-poròtjo of Toren van Babel en kleineren) en de Noorder-Lòda-eil. (Döi, Tuakaru. Dagasuli, Salangade en kleineren). Er wordt gewoonlijk gesproken en geschreven over het district Lolòda, maar de bewoners zeggen Lòda. De naam heeft geen roemrijke beteekenis. In de naburige dialecten beduidt het woord: vluchten, wegloopen. Het is daarom wel eigenaardig, dat het woord lòda in dit dialect geschrapt is en het sa a li-woord (wisselwoord - gebruikt als het oorspronkelijk woord niet mag gebezigd worden, omdat het gelijkt op den naam van een ouder lid der schoonfamilie) djòdjara (in het verwante Galèla'sche dialect: gogòra = hard loopen) er voor in de plaats is gekomen.

De bewoners van het district worden verdeeld in 4 stammen: Baru, Bakulu, Kédi en Laba. De stammen Kédi en Laba wonen in de heuvelen, die de baai van Lòda in het Zuiden begrenzen; de stam Bakulu woonde eertijds grootendeels om de hoofdplaats Lòda, in 't Noorden van de Lòda-baai, aan de Lòda-rivier, gelegen, maar heeft zich noordelijk in het binnenland en langs de kust verspreid tot Baratàku; de stam Baru eindelijk woonde vroeger te Gam-Kahe, maar is ook noordelijk nitgezwermd, langs de kust tot Supu. Onder den laatsten stam wonen, op het eiland Dagasuli en in de negory Potjau een aantal Orang-Gorap (zie de Clercq "Bijdrage tot de kennis van de res. Ternate"); en op het eiland Döi, in de kampong Dàma, vindt men eene Galèla'sche nederzetting. Kleinere nederzettingen van inwoners van Galèla, die er komen visschen, vindt men ook nog tusschen het eiland Diti en de baai van Baratàku. In het binnenland, op de bergen, vindt men, als bijna overal op Halmaheira, verspreide leden van den 
Tobaru-stam, de eigenlijke Berg-Alfoeren, die hunne werkelijke woonplaats hebben in de vlakte van Tbu. Het district Lòda (het grootste van Noord-Halmaheira) is zeer dun bevolkt. Het getal inwoners kan ik niet opgeven, maar naar mijne schatting zal het getal weerbare mannen de 3000 niet te bovengaan.

In de andere districten van Noord-Halmaheira dragen de districtshoofden den naam van Sangadji, maar die van het district Lòda heeft den titel van Kolano (Radja). Het is zeer wel mogelijk, dat hij vroeger een der voornaamste was, onder de vorstjes van Halmaheira en lang zijne onafhankelijkheid heeft weten te bewaren, maar nu is hij, evenals de anderen, vasal van Ternate. Een Ternataansch hoofd (soms een Oetoesan, soms een Djoeroe-toelis) is hem ter zijde gesteld en dat hoofd is in den districtsraad voorzitter; de Kolano heeft daar een adviseerende, maar het Ternataansche hoofd de beslissende stem. Toch staat de Kolano in eene bizondere betrekking tot Ternate, in zooverre de belastingen en heerediensten in de andere districten allen Ternate ten goede komen, terwijl in 't Lòdasche slechts de stammen Bakulu, Kédi en Laba eene geringe belasting aan Ternate te betalen hebben (ik meen uit elken stam jaarlijks van één gezin 10 réalen van f 1.60 - de gezinnen wisselen elkander daarbij om het jaar af tot allen aan de rij geweest zijn). De Kolano van Lòda heeft voor zich het profijt van de heerediensten dier stammen: bouwen van woningen en vaartuigen, in orde houden zijner hoofdplaats, maken van tuinen, roeien op zijn vaartuigen, enz. en daarbij kan hij van den stam Baru de belasting voor zich houden (per gezin 50 cents, benevens een pak sago, eenige maten rijst, een mat, een wan, een zeef en meerdere attributen); ook geeft de stam Baru jaarlijks 6 man om ééne maand heerediensten te presteeren bij den Radja in zijne hoofdplaats. Voorts reist de Kolano rond om rechtszaken te beslechten en steekt van de opgelegde boeten het leeuwendeel op, terwijl het overige daarvan onder de door hem aangestelde dorpshoofden verdeeld wordt. Eene eigenaardige bate trekt hij uit de huwelijken van de schoonen uit zijn rijk, die door mannen uit andere districten begeerd worden. Vindt er zoo'n huwelijk naar 't buitenland plaats, dan wordt de te betalen bruidschat met 10 realen verhoogd, die den Kolano ten goede komen, omdat hij eene onderdane verliest. Hij heeft dus, zooals we zien, privileges boven de hoofden der andere districten.

De Lòdareezen zijn Heidenen. Hun vroegere vorsten waren dat 
ook, maar, naar men mij heeft medegedeeld, is de grootvader van dezen Kolano, op z'n ouden dag, tot den Islam overgegaan. Dit vond weinig navolging bij zijn onderdanen, slechts een klein getal, in zijne omgeving op de hoofdplaats wonende, hangt dit geloof aan. Daar is ook een kleine moskee, waaraan een imam verbonden is. Hier en daar treft men een Mohamedaansch handelaar aan, die er zich van elders vestigde. Sedert 1898 zijn er uit den stam Baru een 300 tal Lòdareezen tot het Christendom overgegaan.

Bij de vier genoemde stammen treft men in het dialect dat zij spreken onderling nog kleine verschillen aan. Het in deze bijdrage behandelde Lòda'sche dialect wordt gesproken door den stam Baru, onder welken stam ik eenige jaren als Zendeling gevestigd was. Zooals men zien zal heeft het groote verwantschap met het Galèla'sche dialect.

Aan deze mijne bijdrage tot vergelijking van het Lòda'sche met het Galèla'sche dialect, heb ik een aantal verhalen toegevoegd, die in 't Lòda'sche in mijn bezit zijn gekomen. De 12 eerste zijn in Lòda'schen tekst, met zoo getrouw mogelijke vertaling. Deze zijn voor mij opgeschreven door de oudsten der scholieren, omdat ik het dialect zoo getrouw mogelijk wilde hebben en ik vreesde er wellicht Galèla'sche elementen in te brengen (omdat ik vlotter met het Galèla'sche dialect te recht kan) indien ik ze zelf in 't Lòda'sch opteekende. Door deze teksten kan dus de beoefenaar zelf zich eenigzins met het Lòda'sch dialect vertrouwd maken. De 2 volgenden werden door een Galèla'schen goeroe (meester) dien ik in 't Lòda'sche, op een filiaal, geplaatst had, opgeteekend met Galèla'schen tekst. Ik heb ze met dien tekst gegeven, opdat de beoefenaar stof tot eigen vergelijking der beide dialecten bij de hand zou hebben. De laatste 17 verhalen heb ik uit den mond van oudere verhalers opgeteekend en gaf daarvan, om boven reeds genoemde reden, geen zelf vervaardigden tekst, doch alleen de vertaling. Ook zòò zijn deze verhalen niet onbelangrijk, daar zij vele overeenkomstige trekken opleveren met de verhalen van andere Indische stammen en volken.

Evenmin als de vroeger door mij nitgegeven "Fabelen, Verhalen en Overleveringen der Galėlareezen" (Tijdschr. v/h. Kon. Inst. v/d. T. L. \& V. van N. I., 6. I.), geloof ik dat deze Lòdasche Verhalen oorspronkelijk zijn. Er komt te veel in voor dat op buitenlandsche toestanden wijst. De bewoners van Lòda maakten hunne vroegere rooftochten meestal naar de Sangir- en Talaut-eilanden, 
ook wel naar Kema, Gorontalo en Midden-Celebes en ik veronderstel dat zij van deze zwerftochten deze verhalen hebben meegebracht. Men verhaalt ze wel zelden meer in Ternataansch dialect, maar waar er namen in voorkomen zijn die meestal Ternataansch of naar 't Ternataansch-taaleigen saamgesteld en als er eene bizonder geliefde uitdrukking of een bewonderd gesprek in voorkomt, worden die gedeelten nog in 't Ternataansch voorgedragen, al vertelt men overigens ook in de eigen taal. Het is daarom (evenals van de Galèla'sche Verhalen) wel aan te nemen, dat de oorspronkelijke Verhalen oud-tijds door de Lòdareezen werden meegebracht in Ternataansch dialect.

Over het geheel genomen zijn deze Verhalen weer andere dan $\mathrm{ik}$ elders aantrof, al vond ik in velen er van kleine trekken van overeenkomst met Verhalen door anderen uitgegeven. Ik heb ze slechts kunnen vergelijken met hetgeen ik van $D^{r} \mathrm{~N}$. Adriani in mijn bezit had. "Sangireesche Teksten." "Étude sur la littérature des To-Radja (Tijdschr. Bat. Gen. deel XL, afl. 4). "Verhaal van Sese n"Taola" (Verhandelingen Bat. Gen. deel LV), enz.

In de laatst-aangehaalde studie van $\mathrm{D}^{\mathrm{r}}$ Adriani, komt in zijn geheel voor het Verhaal, dat men in dezen bundel onder $\mathrm{N}^{\circ} 28$ vindt. $\mathrm{Ik}$ stond het Z.W.Ed. Gel. gaarne voor zijne belangrijke studie af. Daar 't echter t'huis hoort onder hetgeen men in 't Lòda'sche aan Verhalen aantreft, meende ik, dat ik het hier niet mocht weglaten.

Alleen $\mathrm{N}^{\circ} 29$ hierachter heeft bepaald dieren (de Walrus en de Pitta-vogel) tot onderwerp en zou wel oorspronkelijk kunnen zijn. Evenwel, ook bij dit Verhaal, al vertelt men het in de landstaal, draagt men constant eenige belangrijke deelen in 't Ternataansch voor.

Zooals reeds in de Gal. Verh. 42, 43, en 54 personen voorkomen, die tijdelijk als dieren vermomd optreden (42 een leguaan, 43 een slang en 54 een varken) vindt men dit ook weer in deze Lòda'sche Verhalen. In 2,3 en 17 komen mannen voor als léguanen (17 is bijna geheel navolging van Gal. Verh. 42, doch onvolledig en in den aanvang afwijkend); in 5 eene vrouw als varken en in 20 een man als slang. Hiervan vindt men overeenkomstige voorbeelden in $\mathrm{D}^{\mathrm{r}}$ A. Et. 29 en S. T. XXXV. De Verhalen 2, 3, 17 en 20 (in overeenstemming met Gal. Verh. 42) hebben allen dezen zelfden trek, dat de Leguaan — in 17 de Slang — aanzoek laat doen om de hand van ééne uit zeven prinsessen, van wie dan telkens de oudsten het verzoek met verachting afwijzen en de jongste het aanneemt. In den verderen gang der Verhalen loopen de avonturen dan weer uiteen. 
Dat menschen, vermomde menschen en dieren zwanger worden op buitengewone wijze, vindt men verhaald in 5 - waar de tijdelijke als varken rondwandelende vrouw zwanger wordt van de urine van een prins (vergel. Et. 30 , waar een muis zwanger wordt van de urine eens konings) - en in $\mathrm{N}^{\circ} 1$ waar eene vrouw bevrucht wordt, door het eten van de mangga-vruchten van een Reus en haar hond door het eten van de schillen dier vruchten.

Reuzen komen in deze Verhalen voor onder twee benamingen: Arasikisa en Kina-bòro of Kina-kina-bòro (wat deze laatste benaming beduidt weet ik niet: Kina is mij niet bekend; in de S. T. vindt ik Kina = visch; bòro is Gal. ei); de Arasikisa's in 1 en 8 , de Kina-bòro's in 4, 12, 18 en 26. Beide soorten jagen en eten menschen. De Kina-bòro's komen getrouwd voor (evenals Ta n'Tolo en Indo i n"Tolo in Sèsé n"Taola). In Et. 34 komt eene Madame Vorace voor die op deze Reuzen gelijkt en vervolgens heeft men dezelfde figuur in $\mathrm{Bake}, \mathrm{S}$. T. XXI. De Kina-bòro in 26 is bij uitzondering eene vrouw, die mij evenwel toeschijnt geen rechte $\mathrm{Kina-bòro} \mathrm{te} \mathrm{zijn} \mathrm{en} \mathrm{meer} \mathrm{te}$ hebben van een weer-wolvin. De Arasikisa's, die we aantreffen in Gal. Verh. 3, Et. 26, S. T. III, schijnen van eene andere soort. In 12 haalt $\mathrm{Kina-bòro} \mathrm{dezelfde} \mathrm{kunst} \mathrm{met} \mathrm{de} \mathrm{schaamharen} \mathrm{van}$ hem en zijne vrouw uit, als Ta nTolo en Indo i nTolo uitvoeren in Sèse nTaola; terwijl ook in 4 van $\mathrm{Kina-bòro} \mathrm{wordt} \mathrm{verhaald,}$ niet dat zijn schaamharen zoo sterk zijn als in 12 en Sese nTaola voorkomt, maar dat zij zeer grof en hard zijn. In 28 heet de held van 't Verhaal wel: $\mathrm{Ng}$ òfa-Rìkisa, maar deze (dezelfde als de Sese nTaola van $\mathrm{D}^{\mathrm{r}} \mathrm{A}$.) heet alleen zoo om zijne reusachtige grootte en sterkte.

Het feit, dat menschen in het luchtruim (soms in den hemel) opstijgen, langs een ladder of langs anderen weg, vindt men in $2,3,17$ en 22. In 2 wordt van een ladder gesproken, maar in de drie andere verhalen wordt een nieuw voertuig vermeld, een: "maligé-sòr o-sòro" = snelvliegend paleis (een hemel- of wolkenwagen?). In 22 stijgt men er mee op tot den hemelheer; in de andere Verhalen schijnt men er mee in het luchtruim te blijven. In 13 vinden de Halve en zijn broeder den weg naar den hemel, maar wordt niet vermeld de wijze waarop zij daar heengaan. In 27 wordt ook wel van een' reis naar den hemel gesproken, maar die wordt niet in werkelijkheid afgelegd. Overeenkomstige feiten, van bezoeken in den hemel, komen voor in Et. 32 en S. T. XXIX.

De oude Vrouw (i Bangkèlé Tu'a) waarvan $\mathrm{D}^{\mathrm{r}} \mathrm{A}$. spreekt, 
in de studie over Sese n'Taola, en die volgens Z.Ed. Gel. een bekende persoon is in de Toradja'sche Verhalen, komt ook in deze Verhalen menigvuldig voor en wel in $3,9,11,20,22$ en 23. Alleen in 11 wordt zij eenvoudig een "oud vrouwtje" genaamd, maar in de andere Verhalen heet zij: "Sumu ma fakiri", hetgeen mij verklaard werd als "put-bewaakster" of "put-wachtster." Zij neemt de verdwaalden of zich tot haar wendenden aan en wordt voorts "grootje" door hen genoemd.

Ook "widadari's" komen in deze Verhalen voor. Immers men zal haar zeker wel zoo kunnen noemen, die (in 22) worden verrast bij het baden, door de jongste der zeven zonen van den versteenenden vader. Dit voorval komt geheel overeen met hetgeen in S. T. XXIX verteld wordt van Bataka, ò̀ hierin dat het kleed van één der schoonen wordt weggenomen en zij het niet terugerlangt, eer zij beloofd heeft hem mee te nemen en zijne vrouw te worden. Ook Ngòfa-djangu-djangu (in 27) verrast badende meisjes, die men ook wel onder de "widadari's" zal mogen rangschikken. Aan één harer ontrooft hij ook de kleeding en wordt haar echtgenoot. Verder schijnen prinsessen zich identiek te gevoelen met deze hoogere wezens: ten minste volgens 3, waar Saribanunu zegt: "als ik een kind der djin's en widadari's ben, "dan moet er, als ik mijn oogen sluit en weer open een "/snel-vliegend-paleis" " voor mij gekomen zijn" - en evenzoo wordt aan * eind van het Verhaal, door haar schoonvader, gezegd: "als zij werkelijk een kind der djin's en "widadari's is, dan zal mijn gouden stoel, als ik haar daarmee "laat halen, niet uit elkaar gaan, maar in het tegenover gestelde "geval wel." - Ook Prinsen (in deze Verhalen en in de Sangirsche) schijnen zich afkomstig van en in verband met die hoogere wereld te gevoelen, daar het telkens uit hunnen mond gehoord wordt: "Wanneer ik werkelijk een koningszoon ben, dan "geschiede ér dit of dat wonder voor mij.". De gedachte, dat Koningen werkelijk van hooger dan menschelijke afkomst zijn, is levendig in de gedachte der Alfoeren op Halmaheira. De eerste koningen zijn zoo maar niet gewoon ter wereld gekomen: zij daalden uit den top van een klapperboom - of van elders - af en verschenen op aarde. De Koningen bezitten wondermacht, in de verbeelding der onderdanen en dit verklaart het gemak, waarmede de inlandsche vorsten (zonder politie of soldaten) hun volkje regeeren, ja zelfs tyranniseeren en uitzuigen. Het machtwoord des Konings kan den mensch dooden; zijn volk door een plaag doen uitsterven; de visschen uit zee doen 
verdwijnen, zoodat zij geen toespijs kunnen vinden - of het merg uit de sago-boomen, zoodat men te vergeefs werkt, om het voedend meel daaruit te bereiden. Voor den Koning van Lòda (die bij zekere gelegenheid een bezoek ontving, per Gouvernements-stoomer, van den Resident van Ternate, door wien hij werd onderhanden genomen, over onrechtmatige handelingen, tegenover zijn onderdanen, die tot het Christendom overgingen) vreesde men, dat. hij door den Resident zou worden meegenomen. De Resident dacht echter daarover niet en bepaalde zich tot eene vermaning. Toen zeiden des Konings aanhangers: de Resident was bevreesd geweest hem mee te nemen, want Z.H.Ed. Gestr. wist wel, dat de wondermacht van hun Vorst groot was en dat zoo hij tegen zijn zin het schip had bestegen, hij het bij die bestijging zou hebben doen omslaan. Van den Sangadji van Gaam-Konor uit ouden tijd werd mij verhaald, dat hij met den blooten voet gaten in een gemetselden muur kon schoppen; dat, toen men hem eens gevangen overvoerde op een schip van de Compagnie, dit schip 10 Engelsche schepen ontmoetten; dat toen de bemanning van het schip der Compagnie geen raad wist, doch hij - het leed vergetende dat men hem had aangedaan - zeide hen wel te zullen helpen, indien men hem van z'n banden bevrijdde; dit deed men en hij bedekte daarop een der kanonnen met een stuk wit katoen, schoot het toen af en met dat ééne schot boorde hij de 10 Engelsche bodems in den grond. Een ander maal was hij met een vloot van eenige honderden prawwen op een krijgstocht, toen men, bij een oversteek, midden op zee gebrek had aan zoet water: hij nam een rotan, boog dien tot een ring, legde dien op de zee, en binnen den omtrek van dien ring, kon men nu zoet water scheppen naar hartelust. Doch genoeg om aan te toonen, dat Vorsten, niet alleen in de oude Verhalen, maar tot op den huidigen dag, worden beschouwd als wezens van bovenaardsche afkomst, met bovennatuurlijke macht toegerust.

In deze Verhalen (7 en 30 ) vindt men gelijkenis met Ét. 31 en S. T. XXIII en XXXIV, in zooverre er verhaald wordt van kinderen, die nog ter wereld moeten komen en aangaande wie door de vaders wordt bevolen, dat zoo het verwachte kind een meisje is, het moet gedood worden. De wraakneming dier kinderen (die toch in 't leven gespaard worden) op den ontaarden vader, treedt in deze Verhalen niet zoo duidelijk aan 't licht; evenwel het eind van 30 duidt er in zooverre op, dat de vader eindelijk, tot loon van zijne onbarmhartigheid, ellendig aan zijn eind komt. 
In 24 dragen de op zeeroof uitgaanden wel voor een deel andere namen, maar het Verhaal is toch verder analoog met wat wij vinden in Et. 15 en S. T. X.

De slecht behandelde stiefkinderen, in S. T. XXII, vinden hun paralel in de in 23 voorkomenden, hoewel het geheele Verhaal verder anders ingekleed is.

Ook in S. T. XXXIV, aan het eind, vinden we een overeenkomstigen trek, in de geschiedenis van Pusang u Kalumpang en hare zuster Abigaelě, met de historie van Kokamòmoko en Angé ma njonjijé in 11, en wel in het hartstochtelijk zoeken van de eene zuster naar de andere, die haar ontvoerd is en in de wanhoop waarin eindelijk de jongste zich zelf en haar huis verbrandt en vooraf te kennen geeft, dat men aan de kleur der opstijgende rook zal kunnen zien, dat zij is omgekomen.

Zeer veel overeenkomst valt ook op te merken in de Verhalen aangaande den "Halve", vermeld in Et. 37 en voorkomend in S. T. XXXIX en ook in deze Verhalen (13), al zijn die Verhalen onderling niet geheel identisch. De "Halve" in 19 is echter een geheel andere persoon.

Het algemeen verbreide Verhaal, in Et. 28 genoemd en in S. T. XVII voorkomend, is zooals men ziet onder eenigzins anderen vorm ook hier weer te vinden in 14 .

In vele dezer Lòda'sche verhalen komen Kaitjili's voor, waarmede een soort Vorsten bedoeld worden. De Vorsten van Ternate voerden vò̀r de invoering van den Islam dien titel (zie F. S. A. de Clercq Bijdrage tot de kennis der Residentie Ternate bl. 147, 148). Tegenwoordig hoort men nooit anders dan Kolano, en voor "Prins" : Kolano ma ngòfa, of Djōu ma ngōfa, voor verdere afstammelingen: Dano. In de S. T. komen voortdurend Kasili's voor, welke benaming $\mathrm{D}^{\mathrm{r}} \mathrm{A}$. steeds vertaalt met: Prins. Daar men nu echter op Halmaheira nooit meer van Kaitjili's hoort, denk ik dat die benaming in deze Verhalen, met de Verhalen, uit het Sangir'sch zijn overgenomen.

Mijne aandacht is gevallen op het in S. T. XVHI voorkomende mĕ sèp a : balspelen. $\mathrm{D}^{\mathrm{r}} \mathrm{A}$. zegt daarvan: "in de Sangir'sche "sprookjes is de gewone wijze, waarop Prinsen naar de hand eener "Prinses dingen, het meedoen aan een balspel, onder hare pintu. "Degene, die den luchtig uit rotan gevlochten bal in de pintu "werpt, krijgt haar." In $\mathrm{N}^{\circ} 6$ dezer Lòda'sche Verhalen, komt het balspel voor onder den naam van sĕs èpa. In het Lod. (en Gal.) 
is s èpa $=$ schoppen. Maar er komt een niet hiervan afgeleid woord sĕsèpa in deze dialecten voor, als benaming van een uit ròtan gevlochten bal met groote openingen, waarmede niet gespeeld wordt, maar waarin de fijn geplukte kalàpa-bast op de jacht wordt meegenomen, om als prop bij de geweerlading te dienen. Mij dunkt die bal kan oorspronkelijk geimiteerd zijn naar het voorwerp, dat men op de Sangi-eilanden gezien had en dat daar voor balspel gebruikt werd. Sang. sèpa $=$ balspelen; afleiding hiervan (naar den regel in deze beide dialecten) sĕs è $\mathrm{a}=$ bal (als benaming van het werktuig-voorwerp - waarmee het spel gespeeld wordt). Voorts dit woord als denominatief sĕ s è pa $=$ balspelen (zooals men ook heeft: bàsu, bijl; to bàsu, ik hak met den bijl; sidé, zeil; mi sidé, wij zeilen, enz.); dus sĕsèpa, bal; djo sĕsèpa, zij spelen met den bal. Ik had mij vroeger al over dit sĕs èpa verwonderd, als niet van s èpa $=$ schoppen, afgeleid, maar mij dunkt het is nu duidelijk dat het uit het Sangirsch is afgeleid en overgenomen. Van Prinsessen in pintu's: hooggelegen vrouwenvertrekken, weet men hier niet. Het blijkt ook dat de Verhaler er geen juise voorstelling van heeft. Hij doet de 7 dochters van een Koning wonen op den minaret van een moskëe. Verder hoort men van die 7 prinsessen niet meer. Dadelijk worden 3 broers daarbij gedacht, eveneens in dit hoog vertrek woonachtig, en hun spel is niet het werpen met den bal, naar het prinsessen-vertrek, maar het er mede spelen op den omloop van den minaret. Mij dunkt het woord: sĕsèpa, voor het balspel, is door de overgeleverde Sangirsche verhalen wel bekend gebleven, maar langzamerhand is voor de navertellers ondnidelijk geworden wat eigenlijk dit balspel was en heeft hun fantasie er maar wat van gemaakt.

Andere trekken van overeenkomst treft men nog aan in Nos 11

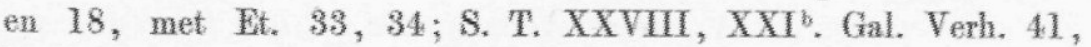
in het achterlaten van voorwerpen of ongedierten, die moeten antwoorden, in de plaats van gevluchte of zich verbergende personen.

Dat tranen levenwekkende kracht bezitten (volgens $\mathrm{D}^{\mathrm{r}} \mathrm{A}$., in "Sese $n$ Tholo", doordien ze dragers zijn van "tanoana = levensfluide), komt ook voor in 27, waar de rijst-meel-pop, door Uriderilako en hare zusters gemakkt, door hare tranen leven ontvangt.

Eigenaardig zijn de tranen, die in goud veranderen, in 28 en 27.

"Varkensplas", in 26, worlt in "t leven teruggeroepen door het hkken der kat en het pikken van den haan; ngo Pitiri-gurungi-

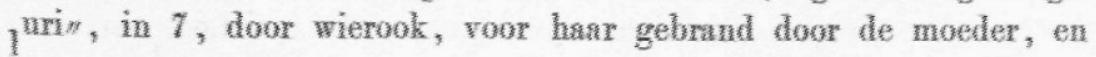


heer "Lèsu", in 30, roept zijne dochter in 't leven terug, door haar te bedekken met een stuk wit en een stuk blauw katoen.

In S. T. XXXVI, wordt Prins Palaka, door den jongen, die hem op 't vlot vergezelt, in het leven teruggeroepen met het afschraapsel van een mangga-pit, dat hij in zijn mond uitperst.

In 3 wordt Saribanunu opgeslikt door een walvisch en naar haar land teruggebracht; evenals de jongste der negen Prinsen in S. T. XXXVIII.

Personen, die elkaar het ongedierte van het hoofd zoeken, waarbij dan de een in slaap valt en de ander verdwijnt, treft men, als in S. T. XXVII, ook aan in 2 en 3.

De eigenaardigheid, die we in 10 en 26 aantreffen, dat door Prinsen te huis gebracht wordende vrouwen, door hare schoonouders worden ontvangen met het eerbetoon van voor haar schotels neer te zetten, waar over heen zij dan naar het huis moeten loopen, is mij niet uit andere Verhalen bekend. Het is toch ook geene gewoonte die op Halmaheira inheemsch is en zij duidt dus wel op buitenlandsche toestanden.

Eindelijk komt ook (in 31 het laatste dezer Verhalen) de Halmaheira'sche Tijl-Uilenspiegel voor den dag. Zijn naam is Tàba. Deze Taba leeft in allerlei beurtgangen bij het roeien (k a bàta) en toch hoorde ik nu eerst zijne geschiedenis of een deel daarvan. Dat de Halmaheirasche Tijl-Uilenspiegel zulke onzedelijke stukken uithaalt, is zeker de oorzaak, dat men ons niet gemakkelijk van hem verhaalde. Voorts, wat er van hem meegedeeld wordt, vindt men voor een groot deel in andere Verhalen terug. Zijn eerste streek gelijkt veel op hetgeen in Gal. Verh. 35 als Kamperstreek van de Voorouders verhaald wordt. Verder vindt men in den uit den waringin-boom antwoordenden geest, in den krommen man dien Tàba zich naar huis laat dragen,' zeer overeenkomstige trekken met den Uilenspiegel van wien Dr. A. in zijn Ét. 35 spreekt, - al zijn die voorvallen hier weer anders ingekleed.

Er zouden nog wel meer paralellen te trekken zijn tusschen de hierachter opgeteekende Verhalen en die welke van Sangi en Celebes afkomstig zijn, maar ik meen hier reeds genoeg aangestipt te hebben, om de geleerden, die van de vergelijkende studie dezer Verhalen werk maken, aan te moedigen ook van de stof, die hem hier aangeboden wordt, gebruik te maken.

Voor een groot deel komen mij deze Verhalen fragmentarisch en zelfs verward voor en zal het mij aangenaam zijn, in dien anderen 
(met deze Verhalen den draad in handen hebbende) wisten op te sporen van welke oorspronkelijke Verhalen het de brokstukken zijn: zooals het Dr. N. Adriani gelukt is, van het, in Gal. Verh. 42, in brokstuk voorkomende Verhaal van het gulzige kind, dat mij vooral aan het eind verward voorkwam, het oorspronkelijke geheel onder de To Radja's uit te vinden.

Zoo hoop ik dus ook met het leveren dezer studie ter vergelijking der Galèla'sche en Lòda'sche dialecten en het geven van deze Lòda'sche Verhalen, anderen van nut te mogen zijn.

Utrecht, Juni 1903. 